\title{
Las metáforas sobre el mundo de la información y los bibliotecarios
}

\author{
Por José-Antonio Gómez-Hernández
}

\begin{abstract}
Resumen: Ensayo sobre el rol del bibliotecario tomando como base algunas de las expresiones metafóricas que se usan para referirse al mundo de la información y los libros. El fin es justificar la función del bibliotecario como faro y especialmente como educador: enseñar, facilitar o mediar para que las personas tengan una cultura de la información, puedan convivir con un ecosistema complejo de información y orientarse en él, siendo compañeros de los otros, entrenando y estando entre los demás. Por eso se juega con una

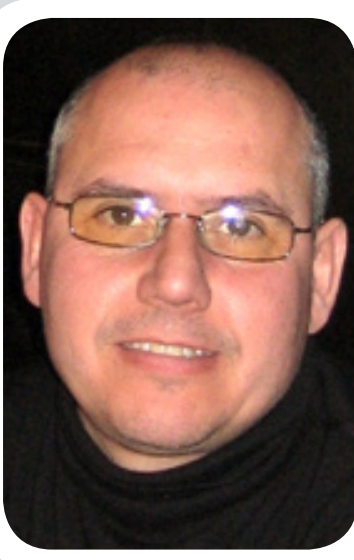

Jose-Antonio Gómez-Hernández es doctor en filosofía pura y licenciado en historia contemporánea. Comenzó como bibliotecario en la Universidad de Murcia en 1984, y desde 1988 es profesor de biblioteconomía en esa universidad. Sus líneas de investigación y publicaciones tienen que ver con gestión de bibliotecas, marketing, servicios bibliotecarios, bibliotecas escolares y universitarias, y alfabetización informacional. Sobre este tema creó el blog Alfin, actualmente alojado en el Foro de promoción de la alfabetización informacional "Alfinred". Miembro del Jurado del Premio Internacional de Marketing de IFLA y de comités científicos de congresos y revistas como Library Review, RED o Anales de documentación. Fue decano de la Facultad de Ciencias de la Documentación (1996-2000), Coordinador de Proyección Cultural (2001-2006), y actualmente es director de la Editorial de la Universidad de Murcia (Editum).

nueva palabra, "entrenauta”, en la que se sintetiza el rol que se defiende.

Palabras clave: Bibliotecarios, alfabetización informacional, metáforas de la información.

Title: Metaphors about librarians and the information world

Abstract: This essay on librarians' roles uses some of the metaphors used to talk about books and the information world as its theoretical approach. The purpose is to justify the role of the librarian as beacon and specially as educator: to teach, to facilitate or to mediate in order to help people improve their information skills for life in the information world, become information literate, and live with other people, training them and still being among them. For that reason we invented a new Spanish word, "entrenauta", with which we synthesized this proposed role.
\end{abstract}

Keywords: Librarians, Information literacy, Metaphors of the information world.

Gómez-Hernández, José-Antonio. "Las metáforas sobre el mundo de la información y los bibliotecarios". En: El profesional de la información, 2008, mayo-junio, v. 17, n. 3, pp. 340-343.

DOI: 10.3145/epi.2008.may.11

EN ESTE TEXTO comento algunas de las expresiones metafóricas que se usan para referirse al mundo de la información, como un modo más de comprender cómo es percibido por la sociedad, y ver qué connotaciones puede ello tener.

Muchos de los términos aluden a la información como problema. Así, es algo que nos desborda, nos ahoga, nos inunda, nos agobia, casi siempre por su exceso o por la dificultad de aprovecharla, y que hace que sea algo donde nos perdemos, nos extraviamos. $\mathrm{Y}$ en respuesta a ello, también hay metáforas de que nos alivian de esa ansiedad: hay faros, rutas para la exploración, planos, guías, brújulas o navegadores.
Defenderé que, además de ser faros, nuestro sentido como bibliotecarios es enseñar, facilitar o mediar para que las personas tengan una cultura de la información, que puedan convivir con un ecosistema complejo de información y orientarse en él, siendo compañeros de singladura de los otros, entrenando y estando entre los demás: ser "entrenautas".

Estas metáforas son conocidas y usadas muy comúnmente; aparecen por primera vez en trabajos teóricos o ensayísticos, o en textos literarios y sociológicos, y luego pasan a los medios de comunicación social o las páginas de internet. Desde estos medios, las que tienen éxito se extienden hacia el lenguaje cotidiano; algunas son acogidas y asimiladas, otras van evolucionando, transformando el sentido inicial o decayendo. No siempre se mencionan con conciencia de su significado implícito, pero creo que resultan bastante ilustrativas de la percepción social del mundo de la información y los libros, y de la riqueza expresiva del lenguaje.

\section{"El crecimiento acelerado} de los libros existentes de la sociedad moderna y contemporánea, hizo decir a Ortega y Gasset que existía una selva salvaje de libros" 


\section{EI libro como fármaco o droga}

Comenzaré con una referencia clásica en la historia del pensamiento, Platón, pues fue el primero que planteó la dimensión del problema del libro (que estaban extendiendo los sofistas en Grecia) considerándolo un "fármaco" del conocimiento en su conocido diálogo Fedro. $\mathrm{Al}$ referirse al libro de esta forma o como medicamento de la memoria, quería explicar el doble significado que para él tenía, que lo hacía ser "droga" y remedio, lo que enferma o cura según se use. Con ello aludía al problema que suponía para el conocimiento su reproducción y transmisión a través de un medio, el libro, que podía no entenderse o ser malinterpretado al alejarse de su autor, al mantenerse en silencio frente a su lector y sus interrogantes. La escritura era una forma de "diseminación" que debía hacerse en una tierra fértil. El fármaco era droga si producía olvido o falso conocimiento, pero un remedio, una ayuda a la memoria, cuando se entraba en diálogo realmente con él.

Por eso podemos hablar de la biblioteca como la "farmacia de Platón", y de una primera expresión dual de la información, algo que será constante en nuestras expresiones: la información es manipulación o el medio para evitarla, granero del conocimiento o causa de indigestión.

\section{Selva, océano y laberinto}

El crecimiento acelerado de los libros existentes, la prensa o sus nuevos medios de reproducción de la sociedad moderna y contemporánea, hizo decir a Ortega y Gasset que existía una "selva salvaje" de libros (la selva selvaggia de la Divina comedia), lo que suponía expresar crecimiento desordenado, frondosidad excesiva, posibilidad de extravío y peligros. Por eso hizo al bibliotecario domador, para aludir a su misión de filtro, de domina- dor de ese exceso, o médico, higienista que administrara su lectura, siguiendo en cierto modo a Platón.

La significación que se ha dado a esta expresión no ha sido única: a veces se ha interpretado que Ortega con ello defendía una función canónica de los bibliotecarios, al servicio de las élites intelectuales, frente a la "rebelión de las masas" que se estaba dando con la extensión de la sociedad democrática. Sin embargo, preferimos considerar que estaba señalando más bien la necesidad de una nueva forma de mediación por el exceso de producción y el riesgo de que su desbordamiento hiciera inaccesible el contenido de los libros.

El que los bibliotecarios somos metáfora del filtro sigue ahí, y es utilizado por la obra más representativa de la idea de difundir de modo abierto el saber, setenta y cinco años después de la Misión del bibliotecario: la Wikipedia, la enciclopedia universal abierta y cooperativa. En efecto, no nos resulta extraño que en la versión española de Wikipedia usen la metáfora de llamar "bibliotecarios" a los que filtran la valía de la información que los participantes aportan, o previenen la información falsa o perniciosa. Son reguladores que hacen que tenga la credibilidad y el valor que perdería si todo valiera y pudiera estar por un igual. Entonces la Wikipedia sería más un paraje asilvestrado que lo que es, un huerto bien sembrado y cultivado por jardineros o agricultores, como reclamaba Platón.

Pero después de Ortega la producción documental siguió aumentando durante el siglo XX (por lo que ya se la definió como explosión) y lo que era selva (tupida pero finita) se fue convirtiendo en ola, torrente, inundación, mar, océano, galaxia y universo de información, con las connotaciones fascinantes, pero sobre todo agobiantes, de lo que es inmenso, y que por ello se nos hace incontrolable o irreductible. Y ello fue compatible, aunque parezca paradójico, con la consideración de nuestro mundo como aldea global, metáfora usada para argumentar que los medios de comunicación transmiten y hacen predominar los mismos contenidos culturales, la misma información y los mismos valores en cualquier lugar del mundo, como cuando compartimos o deseamos la misma Coca-Cola, Levi's, camiseta del Barça o del Madrid y seguimos las mismas noticias.

Otras veces se habla de laberinto de la información, lo que añade un matiz diferente: como la selva, que puede ser abarcable pero tiene muchos vericuetos, el laberinto es un lugar de pérdida que requiere un explorador que nos guíe, nos dé una clave, nos revele el orden, un hilo conductor, "un hilo de Ariadna".

\section{Metáforas de la biblioteca}

Históricamente, la propia biblioteca ha sido, por una parte, aludida metafóricamente, y por otra, usada ella misma como metáfora. La más extendida es laque la ha comparado con un templo, asociándole valores espirituales, como espacio del pensamiento, de la producción inmaterial de los hombres, fruto de su razón. Ello es lógico, pues los libros han tenido el halo de lo sagrado en sociedades donde ha primado una religión con un libro sagrado donde se contenían sus principios y normas, o la palabra de sus fundadores. En ese contexto los bibliotecarios a veces fueron sacerdotes o guardianes de las palabras, lo que suponía destacar su función conservadora y el ritual del acceso al libro y sus misterios. La exageración de ello permitió a veces también considerarla cementerio, si los libros no llegaban a ser leídos y permanecían en los estantes, muertos a la espera de un lector que los vivificara.

Y la biblioteca también ha sido ella misma metáfora, y en concreto de dos ideas contrapuestas: expresión del orden de las cosas, al ser el 
lugar donde se sistematizaba el conocimiento (la Biblioteca de Alejandría sería el ejemplo de ese orden), pero también de la inasibilidad o la infinitud (la borgiana Biblioteca de Babel). Y hoy se habla de la Web como gran biblioteca universal, si bien desordenada o selvática.

\section{Derivaciones, usos e intenciones de las metáforas}

Cuando alguna metáfora se impone, se va ampliando su uso aprovechando los términos que forman parte de su campo semántico. Así, en los océanos las personas navegan como marinos, naufragan, bucean, nadan, se hunden o se ahogan. Por eso tenemos también navegadores, internautas, cuadernos de bitácora como los nuevos blogs o diarios de nuestra navegación, cartas náuticas y "faros", la metáfora de las bibliotecas según la Declaración de Alejandría de 2005. Todo este océano de información ha sido creado por la expansión de internet, que se identifica con una red por la articulación de millones de ordenadores. Como tal red, es un lugar donde por cierto también podemos quedar atrapados o paralizados como en una telaraña.

El poder de la información también se expresa metafóricamente: quien la tiene es fuerte, como un tornado o un tsunami, que arrastra e inunda lo que se encuentra, o es capaz de sobrevolar como un águila el espacio enorme de un gran desierto, como en la reciente campaña publicitaria de un grupo de comunicación. Sin embargo, la mayor parte de las veces es fácil sentirse, ante un océano tan inmenso, como algo pequeño, en parte impotentes para desenvolverse con buena dirección, sin "encontrar el norte". Nos limitamos a flotar como "leños perdidos, que el mar anega o levanta, libremente", según el verso de Cernuda.

Otra figura de éxito para referirnos a la sociedad digital es la de brecha, usada para explicar la existencia de una ruptura, barrera o frontera que divide a los que poseen ordenadores y están conectados a internet (enganchados sería la metáfora de la adicción si lo hacen demasiado), y los que no pueden usar las tecnologías en la comunicación $\mathrm{y}$ en la mejora de sus condiciones personales, sociales y familiares. Y otra metáfora dicotómica en el mundo digital es el de nativos e inmigrantes digitales, lo que atribuye un significado meramente generacional, de edad, al modo de usar las tecnologías: el nativo ha nacido ya en el mundo digital y su utilización es supuestamente espontánea o natural, mientras que el inmigrante es alguien que quiere formar parte de ese mundo y tiene que integrarse en él con esfuerzo, pues no domina sus normas, su lenguaje o sus claves.

Como puede verse, el lenguaje y sus expresiones no son neutrales, pues en este caso, en concreto, simplifican el problema de lo que es un buen uso de las tecnologías. Crean la apariencia de que los nativos ya nacen formados en las tecnologías y no necesitan más orientación para dominarlas o comprender su significado (cuando son muchas veces consumidores compulsivos), y ponen en situación de inferioridad a los que por su edad no han convivido desde la infancia con los ordenadores o tienes posturas críticas ante las tecnologías.

Observamos cómo, en la mayor parte de las ocasiones, solemos expresarnos sobre la información con términos dicotómicos: hay nativos e inmigrantes. Pobres y ricos en información. Un problema, la abundancia de información, y una solución, las tecnologías que la organizan, o los sistemas que nos facilitan la que necesitamos. Nos podemos extraviar, pero también encontrar una solución, una respuesta, la solución a un enigma, la salida del laberinto. Hay un océano enorme, pero por el que se puede navegar, llegar a puer- to, encontrarse. La información es poderosa pero podemos manejarla.

Esto refleja una cierta ingenuidad, pero también es bastante comprensible en el contexto social en que vivimos. Los que hablan en esos términos, se presentan, tras describir el problema, como parte de la solución, y así se legitiman. $\mathrm{Si}$ se nos usa, se nos aprovecha o se nos consume, las personas van a superar su carencia o su problema de información, van a comprender mejor, o van a conseguir sus objetivos. En nuestro mundo actual se nos crean continuamente necesidades, problemas y deseos, e inmediatamente se nos propone el producto que le dé satisfacción. Se nos induce a creer que podemos tener un remedio, un fármaco que no es droga, una respuesta inmediata que calme nuestra ansiedad informativa, o reduzca nuestra incertidumbre. $\mathrm{Y}$ a ser posible, que sea accesible y fácil de consumir, como son las máquinas expendedoras de café (metáfora de la biblioteca encantada con la tecnología que oí hace poco a Lluís Anglada), en las que con una moneda y apretando un botón tienes tu bebida con el azúcar, la leche o la espuma deseadas.

\section{Los bibliotecarios como "entrenautas"}

Obviamente, no todo es tan sencillo como nos puede hacer creer la metáfora del mar y el faro. Para llegar a puerto, además de seguir la luz del faro que nos ilumina o nos indica el camino, hay que conocer el puerto al que queremos llegar, saber acercarse a la costa navegando sin chocar con otros, mantener la ruta, desoír los cantos de sirena, entender las señales del faro y evitar los arrecifes. Hay que saber navegar con el barco hasta él para que nos pueda ser útil. Y el mar no es algo que esté ahí, preexistiendo a nosotros, esperando a que lo surquemos. Nosotros somos también parte del mar, somos quienes alimentamos o 
contaminamos ese mar con nuestros contenidos y nuestro uso de él, y se trata no sólo de llegar, de la meta o el resultado, sino de disfrutar la singladura, nuestro recorrido náutico por el mar de la información.

Con esto llego a la función educativa que tenemos los bibliotecarios y en general los profesionales de la información. Debemos ayudar a los ciudadanos, en un mundo de información desigual e incontrolable, a orientarse por sí mismos y a participar en él de una manera integrada, cooperativa, reflexiva, consciente e intencional. Tarea que por cierto también se ha ido expresando con metáforas diferentes conforme ha evolucionado conceptualmente. Lo que se denominaba formación de usuarios con una dimensión más instrumental o adiestradora que realmente capacitadora, ahora se denomina alfabetización, competencia o cultura informacional, es decir: conocer y saber desenvolverse en el mundo de la información y sus claves. Como ya se decía hace años utilizando otra metáfora clásica: no era cuestión sólo (aunque también) de dar un pez, sino de enseñar a pescar. Luego se convino en que había también que dar la caña. Pero ahora no somos sólo pescadores, sino que estamos nosotros mismos en el mar de la información produciendo, consumiendo o comunicando contenidos, e interactuando de diversas formas. Hay un ecosistema complejo de la información con sus propias reglas, inestabilidades y evolución.

\section{"Me gustaría representar la función del bibliotecario en este ecosistema marino como compañero de singladura y práctico que ayuda a llegar al puerto"}

Por eso me gustaría poder representar la función del bibliotecario en este ecosistema marino como compañero de singladura y práctico que ayuda a llegar al puerto. Si- guiendo el juego con las palabras, propongo que seamos "entrenautas", pues podemos formar, orientar, entrenar, en el mar de la información, estando "entre" y "dentro" de la comunidad de usuarios. Y "entre" otros profesionales con los que compartimos muchas cosas: docentes, periodistas, publicistas, editores. Siendo uno más de los que tejen una cadena interminable de aprendizajes, apoyos, creaciones, publicaciones. Desde un enfoque cooperativo, navegando y construyendo comunidades de aprendizaje en las que vayamos siendo capaces de vivir orientados, conviviendo tanto con la incertidumbre como con el aprendizaje permanente, sabiendo encontrar sentidos.

José A. Gómez-Hernández, Universidad de Murcia, Facultad de Coтиnicación y Documentación, Campus de Espinardo, 30071 Murcia.

jgomez@um.es

http://www.um.es/gtiweb/jgomez/ http://www.alfinred.org/blog http://www.editum.es/blog/

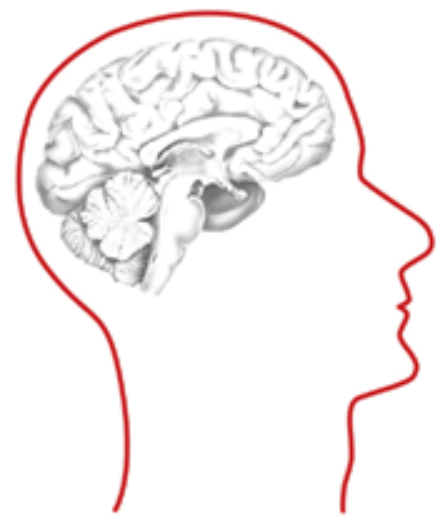

\section{Sale al mercado el Anuario ThinkEPI 2008}

\section{Nueva recopilación de notas ThinkEPI y de las noticias de que determinan el futuro de la Biblioteconomía y la Documentación}

\begin{abstract}
Selección de notas de IweTel, revisadas y actualizadas añadiendo los hitos profesionales más importantes, estadísticas básicas para medir la situación, comentarios y noticias provenientes de diversas fuentes en un esfuerzo recopilatorio único en nuestro idioma.
\end{abstract}

Haga su pedido en http://www.thinkepi.net/anuario.html 